Article

\title{
Growth Rate of Gravity Wave Amplitudes Observed in Sodium Lidar Density Profiles and Nightglow Image Data
}

\author{
Fabio Vargas ${ }^{1, *,+(\mathbb{C}, \text { Guotao Yang }}{ }^{2}$, Paulo Batista ${ }^{3}$ and Delano Gobbi ${ }^{3}$ \\ 1 Department of Electrical and Computer Engineering, University of Illinois at Urbana-Champaign, \\ Champaign, IL 61820, USA \\ 2 State Key Laboratory of Space Weather, Chinese Academy of Sciences, Beijing 100036, China; \\ gtyang@spaceweather.ac.cn \\ 3 National Institute for Space Research, São José dos Campos 01000-000, Brazil; paulo.batista@inpe.br (P.B.); \\ delano.gobbi@inpe.br (D.G.) \\ * Correspondence: fvargas@illinois.edu \\ $\dagger$ Current address: 306 N. Wright St., 5066 ECEB, MC-702, Urbana, IL 61801, USA.
}

Received: 22 October 2019; Accepted: 26 November 2019; Published: 28 November 2019

\begin{abstract}
Amplitude growth rates of quasi-monochromatic gravity waves were estimated and compared from multiple instrument measurements carried out in Brazil. Gravity wave parameters, such as the wave amplitude and growth rate in distinct altitudes, were derived from sodium lidar density and nightglow all-sky images. Lidar observations were carried out in São Jose dos Campos $\left(23^{\circ} \mathrm{S}, 46^{\circ} \mathrm{W}\right)$ from 1994 to 2004, while all-sky imagery of multiple airglow layers was conducted in Cachoeira Paulista $\left(23^{\circ}\right.$ S, $\left.45^{\circ} \mathrm{W}\right)$ from 1999-2000 and 2004-2005. We have found that most of the measured amplitude growth rates indicate dissipative behavior for gravity waves identified in both lidar profiles and airglow image datasets. Only a small fraction of the observed wave events ( $4 \%$ imager; $9 \%$ lidar) are nondissipative (freely propagating waves). Our findings also show that imager waves are strongly dissipated within the mesosphere and lower thermosphere region (MLT), decaying in amplitude in short distances $(<12 \mathrm{~km})$, while lidar waves tend to maintain a constant amplitude within that region. Part of the observed waves (16\% imager; $36 \%$ lidar) showed unchanging amplitude with altitude (saturated waves). About $51.6 \%$ of the imager waves present strong attenuation (overdamped waves) in contrast with $9 \%$ of lidar waves. The general saturated or damped behavior is consistent with diffusive filtering processes imposing limits to amplitude growth rates of the observed gravity waves.
\end{abstract}

Keywords: all-sky imager; sodium lidar; gravity waves; mesospheric nightglow; amplitude growth rate; wave dissipation

\section{Introduction}

Gravity waves play an important role in atmosphere dynamics due to their ability to transport momentum and energy from the lower to the upper atmosphere. Their influence on the mesosphere and lower thermosphere region (MLT), extending from 80-100 km, include heating through turbulence generated by breaking waves, transport and mixing of constituents, reversal of the zonal mean jets, and mean flow acceleration/deceleration through momentum flux transfer to the mean flow, modifying the dynamical conditions at those altitudes [1,2].

Nondissipating waves (freely propagating modes) are expected to increase their amplitudes as $\sim \exp (\alpha z)$, where $\alpha=\frac{1}{2 H}$ is the amplitude growth rate obtained from the linear gravity wave theory [3], $z$ is the altitude, and $H$ is the atmosphere pressure/density scale height. The wave 
amplitude increases to preserve energy in response to the atmospheric density decreasing with the altitude. Typical value of $H$ is $\sim 6 \mathrm{~km}$ in the MLT, which translates into $\alpha=8.3 \times 10^{-2} \mathrm{~km}^{-1}$. As a consequence, a wave generated at $10 \mathrm{~km}$ will have an amplitude $\sim 349$ times larger at the mesospheric region $(\sim 90 \mathrm{~km})$.

Frequently, instability processes (i.e., convective and/or dynamical), or diffusion (atmospheric viscosity) impose limits to the amplitude growth of gravity waves. Thus, departures from $\alpha$ (the amplitude growth of freely propagating waves) are observed, indicating that the wave is being dissipated. Reference [4] investigated high-frequency gravity waves (periods less than one hour) disturbing the mesopause temperature by using wind/temperature lidar measurements. They showed that gravity waves are basically saturated (no change in the wave amplitude over the observed altitude range) to damped (amplitude decreasing with altitude) below $100 \mathrm{~km}$ of altitude, while are unsaturated to freely propagating above that level.

Additionally, Reference [5] showed that waves presenting periods of less than $12 \mathrm{~h}$, observed in $\mathrm{OH}(6-2)$ and $\mathrm{O}_{2}(0-1)$ airglow rotational temperatures, tend to be strongly dissipated throughout the year. For reference, the nominal centroids of the mesosphere airglow layers are $87 \mathrm{~km}(\mathrm{OH}), 94 \mathrm{~km}\left(\mathrm{O}_{2}\right)$, and $96 \mathrm{~km}\left(\mathrm{O}\left({ }^{1} S\right)\right)$ based on measurements and simulations, e.g., [6-8]. Gravity wave characterization has also been carried out using simultaneous measurements of the $\mathrm{OH}$ and $\mathrm{O}_{2}$ airglow intensity and respective airglow rotational temperatures by [9]. These simultaneous measurements of the $\mathrm{OH}$ and $\mathrm{O}_{2}$ emissions were utilized to infer wave growth and dissipation, respectively. Reference [9] also reported a high variability in the wave amplitude growth within a short altitude range of $7 \mathrm{~km}$, i.e., the spatial separation between $\mathrm{OH}$ and $\mathrm{O}_{2}$ layer centroids.

In this paper, we use two different instruments (a Na lidar system and a nightglow all-sky imager) to estimate wave amplitudes and amplitude growth rates of gravity waves disturbing the atmospheric fields at different altitudes in the MLT region. The lidar and the imager sample different regions of the gravity wave spectra and provide complementary information about gravity wave propagation and dissipation in Na density and airglow intensity data, e.g., [10]. The goal of this paper is to discuss the dissipation characteristics of waves in these two distinct spectral ranges. The derived results also give insights about the limiting processes taking place in the atmosphere in response to increasing wave amplitudes.

\section{Instrumentation and Methodology}

Gravity wave intrinsic parameters (intrinsic period, intrinsic phase velocity, vertical wavelength), amplitudes, and amplitude growth rates were obtained from lidar and all-sky imager data. As both instruments provide wave amplitudes at different heights, amplitude growth rate of waves may be estimated by

$$
\beta=\frac{\ln \left(A_{2} / A_{1}\right)}{\Delta z}
$$

where $A_{1}$ and $A_{2}$ are the amplitudes of a gravity wave at the altitude levels 1 and 2, respectively, and $\Delta z$ is the distance between these levels. Here, we refer to $\beta$ as the growth rate of monochromatic waves in general, to distinguish from $\alpha=\frac{1}{2 H}$, the growth rate of nondissipative (freely propagating) waves.

A Na lidar system located in São Jose dos Campos $\left(23^{\circ} \mathrm{S}, 46^{\circ} \mathrm{W}\right)$ provided sodium vertical density profiles from the place where 45 monochromatic vertically propagating gravity waves were observed from 1994 to 2004. The Na lidar vertical density profile reported by [11] was used by [12] to derive the gravity wave parameter for the referred 45 gravity wave events. These wave parameters are used here and compared with the results from the airglow image data.

Figure 1 shows how the monochromatic waves are identified in sodium lidar data. Figure 1a shows a temporal series of sodium lidar vertical density profiles from 75-110 km, with temporal resolution of $3 \mathrm{~min}$ and spatial resolution of $250 \mathrm{~m}$. The sodium density profiles are first spatially and temporally low-pass filtered with cutoffs of about $1.5 \mathrm{~km}$ and $20 \mathrm{~min}$, respectively. Coherent downward phase progression can be seen in Figure 1 by the descending straight red lines. Additionally, 
Figure $1 \mathrm{~b}$ shows a single $[\mathrm{Na}]$ profile superposed to an estimated unperturbed $\overline{[\mathrm{Na}]}$ profile, which correspond to the average of seven profiles around the analyzed time. The relative wave amplitude perturbing the Na layer is given in Figure 1c, showing a decreasing wave amplitude as it propagates upward because the wave phase descends with time as shown by the red thin lines in Figure $1 \mathrm{a}$. For this specific case, the wave presents vertical wavelength $\lambda_{z}=4.6 \mathrm{~km}$, amplitude of $2.46 \%$ relative to the ambient density (at $90 \mathrm{~km}$ ), and inverse growth rate $\frac{1}{\beta}=-24 \mathrm{~km}$. Wave periods, horizontal wavelengths, and phase velocities can also be estimated using the technique described by [12].
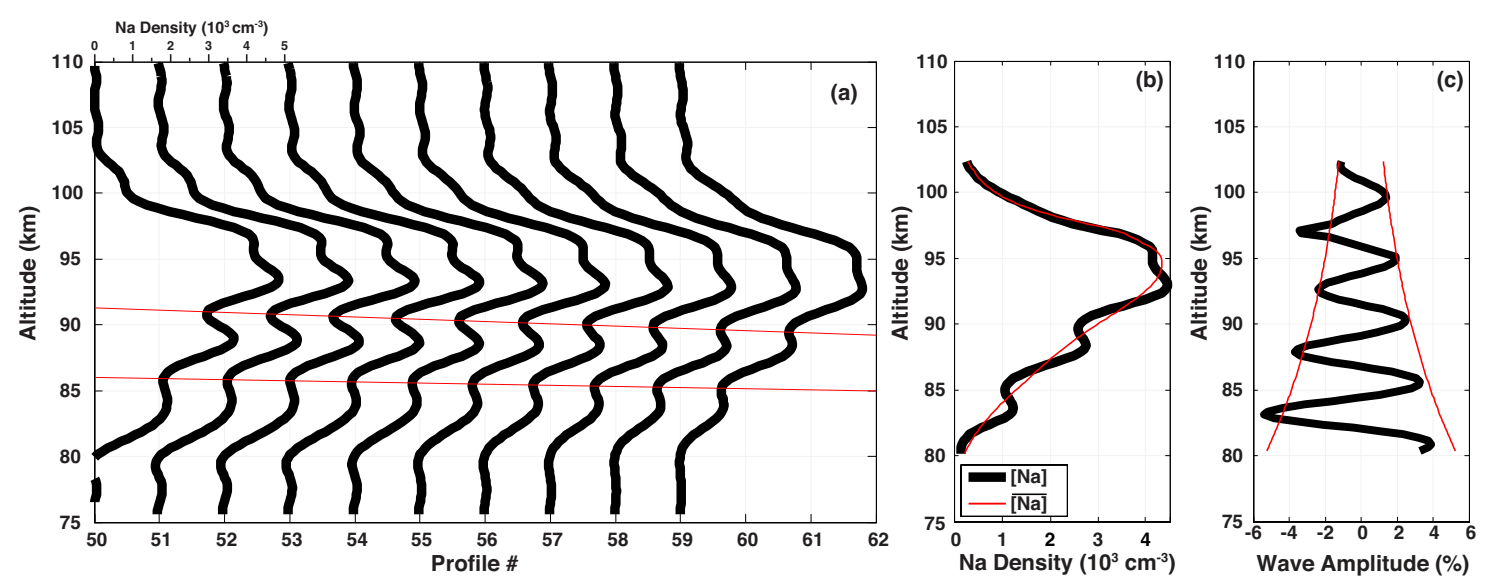

Figure 1. (a) Observed sequence of sodium density profiles taken on 30 May 1996 by a Na lidar system. The descending phase of the wave is indicated by the straight red lines. (b) A single Na density profile superposed by an estimated background profile. (c) Wave amplitude obtained from (b). Notice in (c) the continuous red line wave envelope indicating the wave amplitude decreasing with altitude, i.e., $\beta<0$.

In addition to the lidar, a multicolor nightglow imager operating at Cachoeira Paulista $\left(23^{\circ} \mathrm{S}\right.$, $\left.45^{\circ} \mathrm{W}\right), 114 \mathrm{~km}$ away from the lidar site, provided images of the mesospheric nightglow layers for three emissions during the years of 1999, 2000, 2004, and 2005. A description of this imaging system is given in [13].

To obtain the wave parameters, we first preprocess the image dataset by performing usual corrections in every image (i.e., unwarping, star removal, coordinate transformation, detrending, and filtering). Reference [14] present the preprocessing methodology used in this study. We focus in wave events occurring quasi-simultaneously in two or three nightglow layers. Figure 2a shows an example of a strong gravity wave simultaneously perturbing the central area of images of three nightglow emissions. We have spatially filtered the image set in order to increase the contrast of wave crests by using the Butterworth filter with cutoff wavenumbers at $\frac{1}{100} \mathrm{~km}^{-1}$ and $\frac{1}{10} \mathrm{~km}^{-1}$. The result of the filtering operation is presented in Figure $2 b$.

Images of the $\mathrm{OH}, \mathrm{O}_{2}$, and $\mathrm{O}\left({ }^{1} \mathrm{~S}\right)$ emissions showing simultaneously prominent gravity wave events are then submitted to $1 \mathrm{D}$ cross-spectral analysis to deduce the wave horizontal wavelength, phase difference at different layers, propagation direction, phase velocity, period, relative amplitude, and amplitude growth rate. Due to differences in integration times and filter wheel sequence cycle for every emission recorded by our imaging system, we have only been able to identify 52 wave events disturbing the three layers in four years of observations. Moreover, vertically propagating waves in image data have a short duration as their phase velocities are generally high, which challenges the observation of waves in the three emissions quasi-simultaneously. 


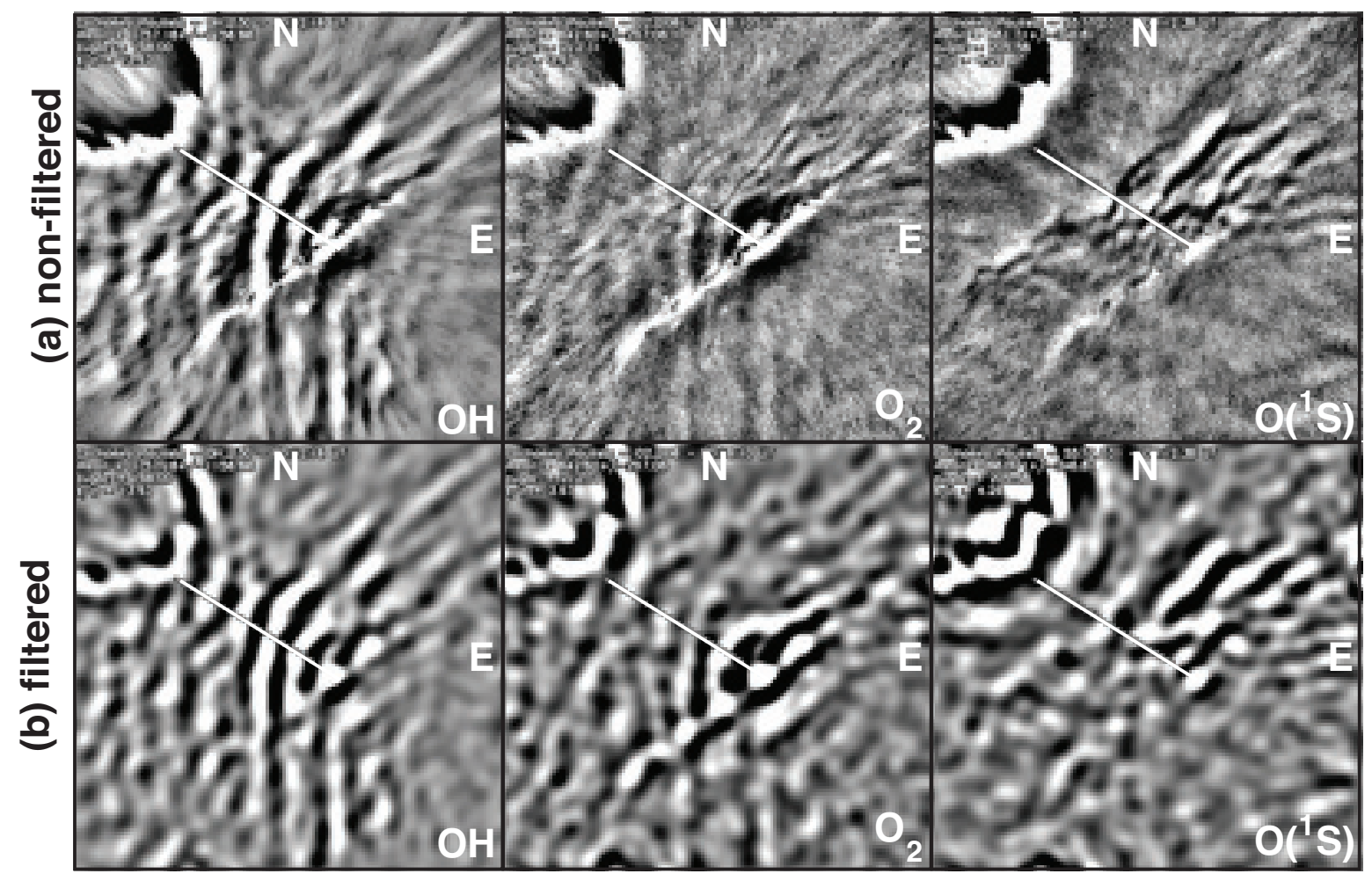

Figure 2. (a) A set of unwarped, nonfiltered all-sky images of the $\mathrm{OH}, \mathrm{O}_{2}$, and $\mathrm{O}\left({ }^{1} S\right.$ ) airglow layers taken quasi-simultaneously on 30 June 2000 at Cachoeira Paulista, Brazil. A large amplitude gravity wave is perturbing all three layers. (b) The same set of images filtered by a Butterworth spatial band pass filter with cutoff wavenumbers at $\frac{1}{100} \mathrm{~km}^{-1}$ and $\frac{1}{10} \mathrm{~km}^{-1}$. The straight lines indicate the pixels whose relative intensity values were extracted to estimate the wave amplitude for each layer.

The wave amplitude is obtained for a given nightglow layer by extracting relative intensity $\frac{\Delta I}{\bar{I}}$ along a straight line drawn perpendicularly to the wave fronts (see Figure 2). These spatial series' of pixel intensities of each layer can be seen in Figure 3a. Each pair of series are then subjected to cross-spectral analysis from where amplitude and phase periodograms are obtained. Figure $3 b, c$ show the amplitude and phase periodograms of the spatial series showed in Figure 3a. The uncertainty in the wave amplitude is less than $20 \%$ according to calculations of [15]. As the layers peak at different altitudes and their separation $(\Delta z)$ is a significant fraction of the wave's vertical wavelength, a finite phase difference is expected to be measured in the phase cross-spectra. The uncertainty in $\Delta z$ is $50 \%$ based on the work of [15] as well.

The location of a spectral maximum in the amplitude periodogram indicates the horizontal wavelength of the dominant wave perturbing the airglow. By integrating the spectrum in the wavenumber range around the dominant spectral peak, we obtain an estimation of the relative wave amplitude. As the vertical distance $\Delta z$ between the centroid of two given airglow layers is known, the amplitude growth rate is estimated by solving $\beta=\frac{\ln \left(A_{2} / A_{1}\right)}{\Delta z}$. As the wave perturbs all three layers at the same time, we observe a finite phase difference for every spatial series pair (Figure 3c). The layer centroid altitudes here have been assumed from simulations of the mesospheric nightglow layers [8]. However, notice that the layer centroids and the relative layers' separation changes slightly with season, location, etc.. For example, see [16].

By applying the procedure above to the images in Figure 2, we have obtained the following parameters for the observed gravity wave event: horizontal wavelength of $\sim 40 \mathrm{~km}$, period of $\sim 30 \mathrm{~min}$, propagation direction of $160^{\circ}$, apparent phase speed of $\sim 20 \mathrm{~m} / \mathrm{s}$, and amplitude of $15 \%, 7 \%$, and $5 \%$ in $\mathrm{OH}, \mathrm{O}_{2}$, and $\mathrm{O}\left({ }^{1} \mathrm{~S}\right)$ layers, respectively, indicating a dissipative wave with $\beta=-15 \times 10^{-2} \mathrm{~km}^{-1}$. 
We refer the reader to the work of $[17,18]$ to find out more details of how wave parameters are derived from the cross-spectral analysis of airglow images.
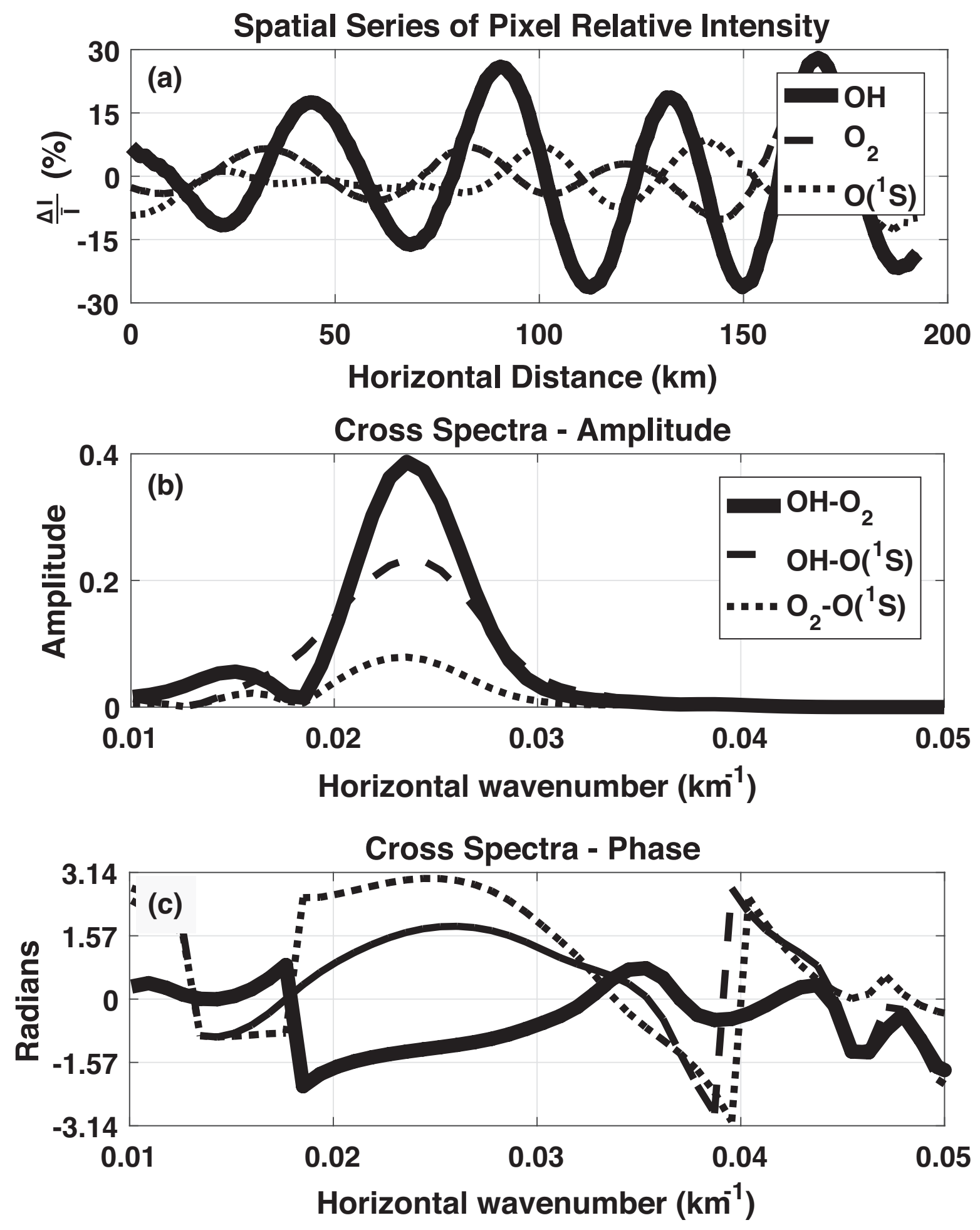

Figure 3. (a) Spatial series of pixel of relative intensity extracted along the wave front disturbing the $\mathrm{OH}, \mathrm{O}_{2}$, and $\mathrm{O}\left({ }^{1} \mathrm{~S}\right)$ airglow layers in Figure 2. (b) Amplitude and (c) phase cross-spectra calculated for each pairs of spatial series of the emissions. A prominent peak is evident at around $0.025 \mathrm{~km}^{-1}$, indicating a gravity wave of $\sim 40 \mathrm{~km}$ horizontal wavelength as the cause of the perturbations. 
We also estimate here the uncertainty of the amplitude growth rate for the wave in Figure 2. Based on [15], an expression for the uncertainty in the amplitude growth ratio is

$$
\sigma_{\beta}^{2}=\left(\frac{1}{A_{1} \Delta_{z}}\right)^{2} \sigma_{A_{1}}^{2}+\left(\frac{1}{A_{2} \Delta_{z}}\right)^{2} \sigma_{A_{2}}^{2}+\left(\frac{\beta}{\Delta_{z}}\right)^{2} \sigma_{\Delta_{z}}^{2}
$$

The relative uncertainties in the amplitudes $\left(\sigma_{A_{1}}, \sigma_{A_{2}}\right)$ and layer separation $\left(\sigma_{\Delta_{z}}\right)$ are $20 \%$ and $50 \%$, respectively. Plugging in these values, we estimate a relative uncertainty $\sigma_{\beta}=56 \%$ for the amplitude growth rate. This represents an upper limit of $\sigma_{\beta}$ once we have used worst-case scenario values for individual uncertainties of interest. This worst-case value for $\sigma_{\beta}$ is taken as an estimation of the uncertainty for all the growth rates derived in this paper.

\section{Results}

There were 45 gravity wave events identified and analyzed from ten years of sodium lidar density profiles [12] as well as 52 gravity wave events from four years of airglow images. Lidar and imager observations were not carried out simultaneously, but this fact does not affect our results since the two instruments sample distinct ranges of the gravity wave spectra, e.g., [10].

Wave vertical scales accessed from lidar measurements are limited by the sodium layer thickness $(\sim 15 \mathrm{~km})$. On the other hand, the shortest accessible vertical wavelength is limited by the signal shot noise [19]. For this reason, the waves identified from lidar data by [12] presented vertical wavelengths in the $2.4-9.3 \mathrm{~km}$ range, with most of these waves $(\sim 40 \%)$ within the $3-4 \mathrm{~km}$ interval. Observed wave periods ranged from $63 \mathrm{~min}$ to $\sim 20 \mathrm{~h}$, with maximal occurrence (66\%) in the 100-300 min range. The horizontal wavelengths fell within the $32<\lambda_{h}<1887 \mathrm{~km}$ range, but with predominant tendency of waves with $\lambda_{h}<200 \mathrm{~km}$. Wave amplitudes ranged from $0.77-8.4 \%$ of the ambient sodium density, with an average of $2.7 \%$.

Gravity wave vertical wavelengths from imager measurements are larger than the airglow layer thicknesses [8]. Typical layer thickness varies from 8 to $10 \mathrm{~km}$. As the observed airglow intensity is given by vertical integration of the volume emission rate of the emission, short vertical scale waves $\left(\lambda_{z}<15 \mathrm{~km}\right)$ are difficult to observe once they self-interfere within the layer. The wave intensity perturbation is strongly attenuated for ground-based observations in that case.

Imagers are able to observe short period waves $(\tau<1 \mathrm{~h})$ and fast phase speeds $\left(c_{o}>40 \mathrm{~m} / \mathrm{s}\right)$. The horizontal wavelength accessed with imager in this study was limited by the field of view of the instrument once we were focusing only on the phase of the wave in snapshots of the airglow emissions taken quasi-simultaneously. Notice, however, that larger horizontal wave scales can be seen via airglow imagery by sampling wave structures over the entire night. The lower limit is determined by the spatial resolution ( $d s)$ of each pixel, which is $1 \mathrm{~km} /$ pixel in this study. Spectral analysis of the events studied here shows $\lambda_{h}$ ranging from $\sim 14$ to $\sim 78 \mathrm{~km}$. The analysis of spatial series extracted from images reveals relative wave amplitudes $\left(\frac{\Delta I}{\bar{I}}\right)$ ranging from $0.6 \%$ to $15 \%$ for the $\mathrm{OH}$, from $0.5 \%$ to $8.5 \%$ for $\mathrm{O}_{2}$, and from $0.5 \%$ to $8.5 \%$ for $\mathrm{O}^{1} \mathrm{~S}$ ) emissions.

Figure 4 shows histograms for the amplitude growth rate $(\beta)$ for waves observed in both imager and lidar data. Positive values of $\beta$ indicate amplitude amplification with increasing altitude, while negative values refer to decay of the wave amplitude with increasing altitude. Values of $\beta \sim 0$ show that the amplitude does not change as the wave propagates upward (saturated wave), while events presenting $\beta>8 \times 10^{-2} \mathrm{~km}^{-1}$ are nondissipating (freely propagating) waves as their amplitude e-folds every $\alpha^{-1}=2 H=12 \mathrm{~km}$ [3]. Finally, waves presenting $\beta>-8 \times 10^{-2} \mathrm{~km}^{-1}$ decay in amplitude rapidly (strong dissipation), losing more than $64 \%$ of their original energy within $2 \mathrm{H}=12 \mathrm{~km}$ distance. 


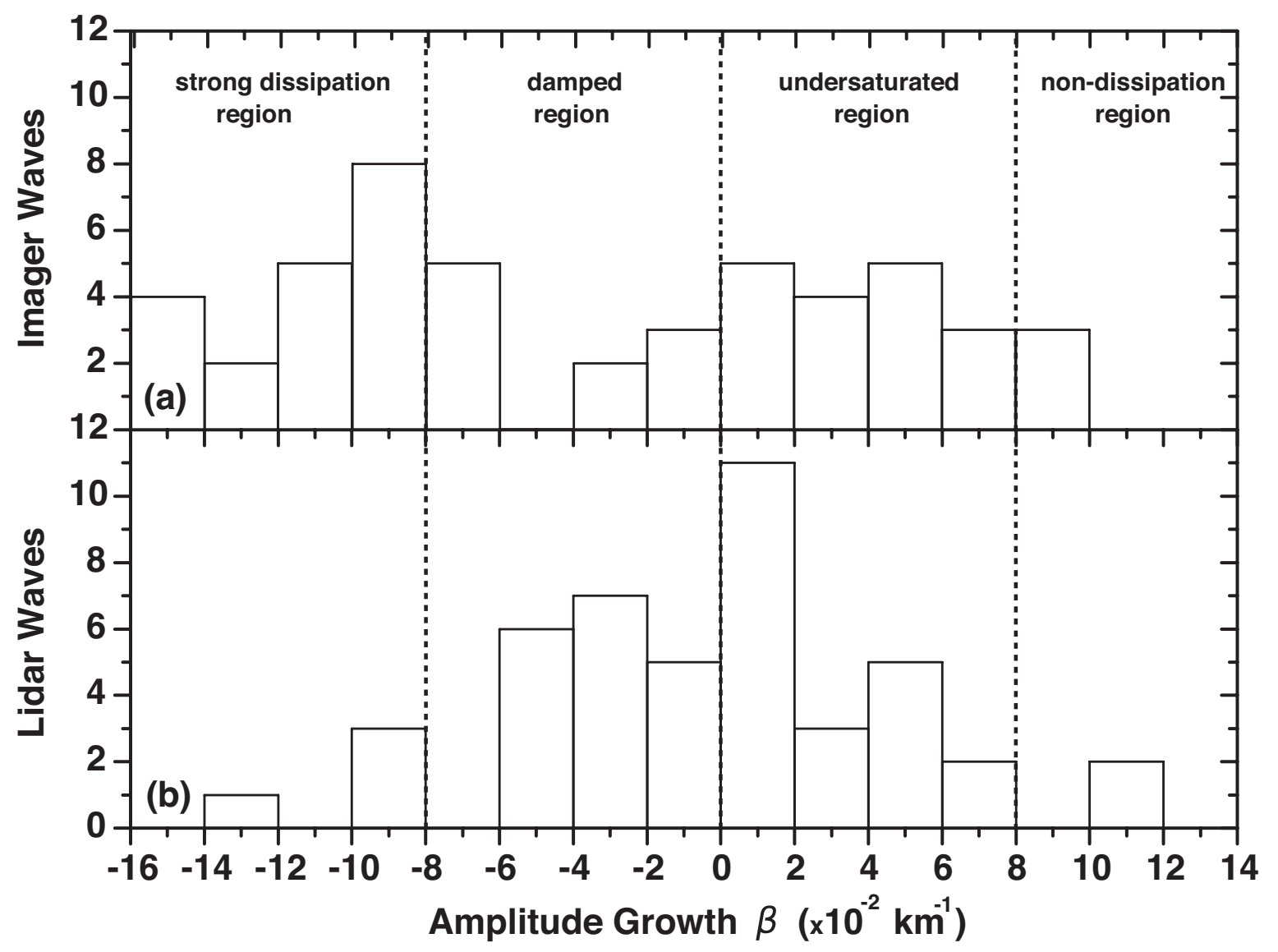

Figure 4. Amplitude growth of waves observed by (a) all-sky imager and (b) sodium lidar. Positive values of the growth rate indicate increasing gravity wave amplitudes. Negative values of $\beta$ indicate amplitude attenuation as the wave propagates upward. Regions of distinct amplitude growth characteristics are indicated in the diagram. The upper limit for the uncertainty in $\beta$ is $\sigma_{\beta}=56 \%$.

Amplitude growth rates derived from lidar waves present $48.9 \%$ of negative values and $51.1 \%$ of positive values, showing a somewhat symmetric distribution of $\beta$. For waves observed in imager data, there are $61.5 \%$ of negative and $38.5 \%$ of positive growth rate values, indicating a slight predominance of damped wave modes. Remarkably, only a small fraction of the observed wave events ( $4 \%$ imager; $9 \%$ lidar) are nondissipative (freely propagating waves), that is, few waves present growth close to the theoretical rate $\alpha=\frac{1}{2 H}=8.3 \times 10^{-2} \mathrm{~km}^{-1}$.

Wave events observed in Na lidar profiles show a maximal occurrence of waves in the range of $[0<\beta<2] \times 10^{-2} \mathrm{~km}^{-1}$ (undersaturated region) that represents $24 \%$ of total lidar waves. These events show amplification with increasing altitude but not as fast as the theoretical growth rate. In contrast, imager waves show the maximal growth rate occurrence in the $[-10<\beta<-8] \times 10^{-2}$ $\mathrm{km}^{-1}$ interval (strong dissipation region), which corresponds to $15.4 \%$ of the imager events.

About $36 \%$ of lidar waves are close to the saturation limit $(\beta \sim 0)$, in contrast with $16 \%$ of imager waves with similar behavior. In addition, $\sim 51.6 \%$ of the imager waves show strong attenuation $\left(\beta<-8 \times 10^{-2} \mathrm{~km}^{-1}\right.$ ) against only $\sim 9 \%$ of waves in the lidar dataset having similar growth rates. This contrast may be caused by the method of analysis used by [12], which is biased towards waves that propagate normal to the wind flow, or are experiencing uniform Doppler shift along the Na layer.

\section{Discussion}

Our results show that imager waves are strongly dissipated within the MLT, decaying in amplitude in short distances $(<12 \mathrm{~km})$. Lidar waves tend to maintain a constant amplitude within the MLT region. 
While nondissipating, propagating waves $\left(\beta>8 \times 10^{-2} \mathrm{~km}^{-1}\right)$ correspond to $9 \%$ and $4 \%$ of the events observed by lidar and imager, respectively, and about $90 \%$ of waves observed in both instruments show dissipative behavior (departures from the nondissipative wave growth rate $\alpha$ ). The wave energy transferred to the media due to dissipative wave processes causes direct effects in the atmosphere, such as mean flow acceleration and local heating. In general, hydrodynamic instabilities and diffusion processes are responsible to limit the wave amplitude.

Imager waves present stronger dissipation than lidar waves in the $\beta<0$ region of the distribution. The fact that imager waves present longer vertical wavelengths $\left(\lambda_{z}>10 \mathrm{~km}\right)$ than lidar waves $\left(\lambda_{z}<10 \mathrm{~km}\right)$ may shed light on this stronger dissipative behavior. Indeed, saturation theories, e.g., $[20,21]$ invoke that various saturation processes constrain wave amplitudes at large vertical wavenumbers (smaller $\lambda_{z}$ ). In the MLT, wave amplitudes may exceed saturation values where large group velocities impose wave amplitude growth that is faster than the time for instabilities to take over the dissipation process. Thus, the dissipation occurs via saturation of the wave amplitude, but neither via wave breaking nor turbulence.

The linear saturation theory (LST) predicts that the wave amplitude will reach the saturation limit when the horizontal perturbation velocity $u^{\prime}$ equals the intrinsic horizontal phase velocity of the wave $c_{i}$. The amplitude is then limited by convective or shear instabilities [20]. On the other hand, the diffusive filtering theory (DFT) states that waves will be severely damped by diffusion when the effective vertical diffusion velocity $m D$ of the particles experiencing the wave motion exceeds the vertical phase velocity of the wave $\omega m^{-1}$ [22]. Here, $D, m$, and $\omega$ are the total effective atmospheric diffusivity, the vertical wavenumber, and the wave frequency, respectively.

In this sense, waves presenting $\omega>m^{2} D$ propagate without attenuation, while waves presenting $\omega<m^{2} D$ are removed from the spectra by diffusion. Our study as well as [12] suggest that gravity waves observed in lidar measurements are in accordance with the DFT, while ruling out the predictions of the LST. However, some observed wave events in the lidar dataset presented peculiar behavior, suggesting that processes other than diffusivity have to be considered to explain the observed wave amplitude characteristics and growth rates.

\section{Conclusions}

Atmospheric gravity waves observed in lidar and imager measurements were analyzed in this study. These instruments sample distinct regions of the gravity wave spectra. A total of 45 monochromatic waves were identified in lidar data; and 52 waves were identified in images of mesospheric nightglow layers. Growth rate distributions for waves observed in lidar are remarkably distinct from those observed in imager data. The main results of this work are:

- About $90 \%$ of the events (for both datasets) are representative of dissipative waves.

- About $51.6 \%$ of imager waves are in the strong dissipation region range $\left(\beta<-8 \times 10^{-2} \mathrm{~km}^{-1}\right)$, against only $\sim 9 \%$ of these type of waves in the lidar dataset.

- Lidar waves show $36 \%$ of the events close to the saturation limit $(\beta \sim 0)$, in contrast with $16 \%$ of imager waves with similar behavior.

- The maximal occurrence of lidar waves $(24 \%)$ is located in the undersaturated region where $[0<\beta<2] \times 10^{-2} \mathrm{~km}^{-1}$.

- The maximal occurrence of imager waves (15.4\%) fall within the interval of $[-10<\beta<-8] \times$ $10^{-2} \mathrm{~km}^{-1}$ in the strong dissipation range of the distribution.

- Gravity waves observed in lidar density profiles support the diffusive filtering theory, which states the dissipation of wave energy is mainly due to diffusivity processes acting on the wave amplitude. Image data are inconclusive for this matter because of the lack of simultaneous background wind measurements to estimate the intrinsic parameters of the imager waves. 
Author Contributions: Formal analysis, F.V.; investigation, F.V. and G.Y.; methodology, F.V. and G.Y.; resources, G.Y., P.B., and D.G.; writing-original draft, F.V.; writing-review and editing, F.V.

Funding: This research received external funding by CNPq grant number 04/07695-5 (Brazil), and National Science Foundation under 1-NSF AGS Grant 17-59573 (USA) and 2-NSF AGS Grant 19-03336 (USA).

Acknowledgments: We are grateful to Capes, and FAPESP, the Brazilian Financial Agencies, that gave support to this work in several ways.

Conflicts of Interest: The authors declare no conflict of interest.

\section{References}

1. Fritts, D.C.; Alexander, M.J. Gravity wave dynamics and effects in the middle atmosphere. Rev. Geophys. 2003, 41. [CrossRef]

2. Fritts, D.C.; Vadas, S.L.; Wan, K.; Werne, J.A. Mean and variable forcing of the middle atmosphere by gravity waves. J. Atmos. Sol.-Terr. Phys. 2006, 68, 247-265. [CrossRef]

3. Hines, C.O. Internal atmospheric gravity waves at ionospheric heights. Can. J. Phys. 1960, 38, 1441-1481. [CrossRef]

4. Swenson, G.; Liu, A.; Li, F.; Tang, J. High frequency atmospheric gravity wave damping in the mesosphere. Adv. Space Res. 2003, 32, 785-793. [CrossRef]

5. Taori, A.; Guharay, A.; Taylor, M.J. On the use of simultaneous measurements of $\mathrm{OH}$ and $\mathrm{O}_{2}$ emissions to investigate wave growth and dissipation. Ann. Geophys. 2007, 25, 639-643. [CrossRef]

6. Greer, R.; Murtagh, D.; McDade, I.; Dickinson, P.; Thomas, L.; Jenkins, D.; Stegman, J.; Llewellyn, E.; Witt, G.; Mackinnon, D.; et al. ETON 1: A data base pertinent to the study of energy transfer in the oxygen nightglow. Planet. Space Sci. 1986, 34, 771-788. [CrossRef]

7. McDade, I.; Murtagh, D.; Greer, R.; Dickinson, P.; Witt, G.; Stegman, J.; Llewellyn, E.; Thomas, L.; Jenkins, D. ETON 2: Quenching parameters for the proposed precursors of $\mathrm{O} 2(\mathrm{~b} 1)$ and $\mathrm{O}(1 \mathrm{~S})$ in the terrestrial nightglow. Planet. Space Sci. 1986, 34, 789-800. [CrossRef]

8. Vargas, F.; Swenson, G.; Liu, A.; Gobbi, D. O(1S), OH, and O2(b) airglow layer perturbations due to AGWs and their implied effects on the atmosphere. J. Geophys. Res. Atmos. 2007, 112. [CrossRef]

9. Reisin, E.R.; Scheer, J. Characteristics of atmospheric waves in the tidal period range derived from zenith observations of $\mathrm{O} 2(0-1)$ Atmospheric and $\mathrm{OH}(6-2)$ airglow at lower midlatitudes. J. Geophys. Res. Atmos. 1996, 101, 21223-21232. [CrossRef]

10. Gardner, C.S.; Taylor, M.J. Observational limits for lidar, radar, and airglow imager measurements of gravity wave parameters. J. Geophys. Res. Atmos. 1998, 103, 6427-6437. [CrossRef]

11. Clemesha, B.R.; Simonich, D.M.; Batista, P.P. A long-term trend in the height of the atmospheric sodium layer: Possible evidence for global change. Geophys. Res. Lett. 1992, 19, 457-460. [CrossRef]

12. Yang, G.; Clemesha, B.; Batista, P.; Simonich, D. Lidar study of the characteristics of gravity waves in the mesopause region at a southern low-latitude location. J. Atmos. Sol.-Terr. Phys. 2008, 70, 991-1011. [CrossRef]

13. Medeiros, A.; Buriti, R.; Machado, E.; Takahashi, H.; Batista, P.; Gobbi, D.; Taylor, M. Comparison of gravity wave activity observed by airglow imaging at two different latitudes in Brazil. J. Atmos. Sol.-Terr. Phys. 2004, 66, 647-654. [CrossRef]

14. Garcia, F.J.; Taylor, M.J.; Kelley, M.C. Two-dimensional spectral analysis of mesospheric airglow image data. Appl. Opt. 1997, 36, 7374-7385. [CrossRef]

15. Vargas, F. Uncertainties in gravity wave parameters, momentum fluxes, and flux divergences estimated from multi-layer measurements of mesospheric nightglow layers. Adv. Space Res. 2019, 63, 967-985. [CrossRef]

16. García-Comas, M.; López-González, M.J.; González-Galindo, F.; de la Rosa, J.L.; López-Puertas, M.; Shepherd, M.G.; Shepherd, G.G. Mesospheric OH layer altitude at midlatitudes: Variability over the Sierra Nevada Observatory in Granada, Spain ( $\left.37^{\circ} \mathrm{N}, 3^{\circ} \mathrm{W}\right)$. Ann. Geophys. 2017, 35, 1151-1164. [CrossRef]

17. Tang, J.; Kamalabadi, F.; Franke, S.J.; Liu, A.Z.; Swenson, G.R. Estimation of gravity wave momentum flux with spectroscopic imaging. IEEE Trans. Geosci. Remote Sens. 2005, 43, 103-109. [CrossRef]

18. Vargas, F.; Gobbi, D.; Takahashi, H.; Lima, L.M. Gravity wave amplitudes and momentum fluxes inferred from $\mathrm{OH}$ airglow intensities and meteor radar winds during SpreadFEx. Ann. Geophys. 2009, 27, 2361-2369. [CrossRef] 
19. Gardner, C.S.; Voelz, D.G. Lidar studies of the nighttime sodium layer over Urbana, Illinois: 2. Gravity waves. J. Geophys. Res. Space Phys. 1987, 92, 4673-4694. [CrossRef]

20. Dewan, E.M.; Good, R.E. Saturation and the "universal" spectrum for vertical profiles of horizontal scalar winds in the atmosphere. J. Geophys. Res. Atmos. 1986, 91, 2742-2748. [CrossRef]

21. Tsuda, T.; Inoue, T.; Kato, S.; Fukao, S.; Fritts, D.C.; VanZandt, T.E. MST Radar Observations of a Saturated Gravity Wave Spectrum. J. Atmos. Sci. 1989, 46, 2440-2447. [CrossRef]

22. Gardner, C.S. Diffusive filtering theory of gravity wave spectra in the atmosphere. J. Geophys. Res. Atmos. 1994, 99, 20601-20622. [CrossRef]

(C) 2019 by the authors. Licensee MDPI, Basel, Switzerland. This article is an open access article distributed under the terms and conditions of the Creative Commons Attribution (CC BY) license (http://creativecommons.org/licenses/by/4.0/). 